\title{
Applying Fuzzy Mathematics to Evaluating the Membership of Existing Reinforced Concrete Bridges in Taipei
}

\author{
Ming-Te Liang \\ Professor, Department of Harbor and River Engineering, National Taiwan Ocean University, Keelung, Taiwan. \\ Jai-He Wu \\ Graduate Student, Department of Harbor and River Engineering, National Taiwan Ocean University, Keelung, Taiwan. \\ Chih-Hsin Liang \\ Ph.D. Candidate, Institute of Material Engineering, National Taiwan Ocean University, Keelung, Taiwan
}

Follow this and additional works at: https://jmstt.ntou.edu.tw/journal

Part of the Civil and Environmental Engineering Commons

\section{Recommended Citation}

Liang, Ming-Te; Wu, Jai-He; and Liang, Chih-Hsin (2000) "Applying Fuzzy Mathematics to Evaluating the Membership of Existing Reinforced Concrete Bridges in Taipei," Journal of Marine Science and Technology. Vol. 8: Iss. 1, Article 3. DOI: $10.51400 / 2709-6998.2450$

Available at: https://jmstt.ntou.edu.tw/journal/vol8/iss1/3

This Research Article is brought to you for free and open access by Journal of Marine Science and Technology. It has been accepted for inclusion in Journal of Marine Science and Technology by an authorized editor of Journal of Marine Science and Technology. 


\section{Applying Fuzzy Mathematics to Evaluating the Membership of Existing Reinforced Concrete Bridges in Taipei}

\section{Acknowledgements}

The authors would like to thank to the National Science Council of the R.O.C for financial support of this study under Contract NSC 89-2211-E-019-015. 


\title{
APPLYING FUZZY MATHEMATICS TO EVALUATING THE MEMBERSHIP OF EXISTING REINFORCED CONCRETE BRIDGES IN TAIPEI
}

\author{
Ming-Te Liang* Jai-He $\mathrm{Wu}^{* *}$ and Chih-Hsin Liang***
}

Keywords: damage, crack, evaluation grade, synthesis evaluation.

\begin{abstract}
In this study, the concept of fuzzy mathematics was applied to the damage evaluation of existing reinforced concrete (RC) bridges. The partition rule of evaluation grade was used to divide the evaluation results. The damage state of existing RC bridges was carried out using a double layer fuzzy synthesis evaluation. Moreover, based on the results of the synthesis evaluation, the damage state of existing RC bridges was thoroughly partitioned. According to the evaluation results, the double-layer synthesis evaluation of fuzzy for the damage of RC bridge is definitely useful. The evaluation results are also offered as the basis for strategy on the repair and reinforcement of existing RC bridges. In order to verify this proposed method, the Huey-tong bridge, Jzyh-chyang bridge, Ay-gwo west road viaduct, and the old Hwan-nan viaduct in Taipei were evaluated. The investigated results indicate that the structural properties of the Huey-tong bridge belong to Grade I, II, III and IV which have the membership value of $0.334,0.300,0.191$ and 0.175 ,respectively. The structural properties of the Jzyh-chyang bridge were attributed to Grade I, II, III and IV which have the membership value of $0.410,0.337,0.168$ and 0.085 , respectively. The Ay-gwo west road viaduct was the properties of Grade I, II, III and IV with $0.363,0.326,0.193$ and 0.118 , respectively. The old Hwan-nan viaduct was the properties of Grade I, II, III and IV with $0.354,0.354,0.198$ and 0.094 , respectively. The order repair and reinforcement is the Huey-tong bridge, Ay-gwo west road viaduct, old Hwan-nan viaduct and Jzyh-chyang bridge. Therefore, the fuzzy mathematics appears the advantage for evaluation the damage state of existing $\mathrm{RC}$ bridge.
\end{abstract}

\section{INTRODUCTION}

After long-term service, existing RC bridges ex-

Paper Received Oct. 28, 1999. Author for Correspondence: M. T. Liang. * Professor, Department of Harbor and River Engineering, National Taiwan Ocean University, Keelung, Taiwan.

**Graduate Student, Department of Harbor and River Engineering, National Taiwan Ocean University, Keelung, Taiwan.

***Ph.D. Candidate, Institute of Material Engineering, National Taiwan Ocean University, Keelung, Taiwan hibit numerous types of wear damage. Civil engineers world wide have devoted much research on the proper evaluation of structural damage in RC bridges. Generally speaking, the degree of existing damage in the $\mathrm{RC}$ bridge studied will help us to make two engineering judgements: First, based on the degree of existing damage, make an accurate determination for repair and reinforcement or replacement. Second, establish the relationship among the damage factors to evaluate the bearing capacity, durability and service performance of existing RC bridges. In existing RC bridges damage usually occurrs design, construction error and outdoor environment. It has become evident that fatigue in existing RC bridges has not always been related to wear damage.

After Zadeh[1965] published fuzzy sets, fuzzy mathematics has been used extensively in numerous investigations. Computational science, the use of fuzzy mathematics was also developed for use in the field of human natural mechanism. Zadeh [1978] pointed out that the mathematical apparatus of the theory of fuzzy sets provides a natural basis for the theory of possibility playing a role which is similar to that of measure theory in relation to the theory of probability. Viewed in this perspective, a fuzzy restriction may be interpreted as a possibility distribution, with its membership function playing the role of a possibility distribution function. A fuzzy variable is associated with a possibility distribution in much the same manner as a random variable is associated with a probability distribution. Zadeh [1979] described that fuzzy reasoning means the process or processes by which a possibly imprecise conclusion is deduced from a collection of imprecise premises. Such reasoning is, for the most part, qualitative ranther than quantitative in nature, and nearly all of it falls outside of the domain of classical logic. Yao [1979] used the concept of structural identification to perform damage assessment and reliability evaluations on existing structures. Yao [1985] presented the theory of fuzzy 
sets as useful in interpreting the safety and reliability of existing structures with membership functions, which can be manipulated in a logical manner to obtain an answer to the original and complex problem. Tharmabala and Nowak [1987] used mathematical models that can conveniently represent a bridge structure using a suitable structure function and (or) reliability network. By introducing the probabilitic concept into the structural function and (or) reliability network, it is shown that it is possible to evaluate a bridge system reliability. The system reliability of a structure with selected component failures can also be evaluated in a fashion similar to a structure without component failures except that the component reliability is adjusted to account for the load redistribution. Shiaw and Huang [1990] adopted the limited state design principle combined with fuzzy evaluation and random variable analysis to determine the bearing capacity index and safety degree of bridge. Jwu et al. [1991] used fuzzy mathematics to determine the reliability of a wharf structure. In order to enhance the evaluation performance, the grade partition method was suggested by Jwu et al. Wang [1992] introduced the theories of fuzzy synthesis evaluation with single, and multiple factors, double- and multiplelayers and their applications in earthquake model. $\mathrm{Qu}$ [1995] studied the fuzzy evaluation of the durability influence of concrete bridges due to cracks. Zhao [1996] provided reliability analysis and fuzzy evaluation for the safety of existing RC structures and established the relative evaluation method. To data, however, no studies have attempted to evaluate the damage state of existing RC bridge without employing double layer fuzzy process. This is a notable defect, because the use of single layer fuzzy process in previous studies may have resulted in underestimation of membership value.

In this study, applying the concept of fuzzy mathematics to establish damage evaluations for existing RC bridges is presented. The partition rule of evaluation grade was used to divide the evaluation results. The damage state of existing RC bridges was executed using the synthesis evaluation of a double-layer fuzzy process. Furthermore, based on the results of the synthesis evaluation, the damage state of existing RC bridges was completely partitioned. According to the evaluation results, the synthesis evaluation of double-layer fuzzy process for the damage of a RC bridge is definitely useful. Meanwhile, the evaluation results are also offered as the strategy for the repair and reinforcement of existing RC bridges.

\section{EVALUATION METHOD OF FUZZY MATHEMATICS}

\section{Evaluation Standard}

For civil engineers and researchers, how to evaluate the safety and degree of damage in an existing structure was a very difficult problem. For this problem, one must first setup a sound evaluation standard. Through this evaluation standard, the safety and degree of structural damage can be measured. During the process of establishing an evaluation standard, the requirements and specifications will be different for researchers and engineers. Therefore, a combination of both groups requirements and specifications is obviously very important. Evaluation grades based on the requirements and specifications of researchers and engineers are described as follows:

Grade I: The outward appearance of the bridge and its member is very good. The member rigidity and bearing capacity are all compliant to design requirements. The safe load and durability are also compliant to code requirements. The bridge is serviceable for continued use.

Grade II: The bridge or its members has some external damage. The member rigidity and bearing capacity are decreased. However, the member rigidity and bearing capacity can attain safe load design requirements. The longterm durability is the only problem. The bridge can be continued in use after some repairs.

Grade III: The outward appearance of the bridge or its members show severe damage. The member rigidity and bearing capacity are decreased. The parts of member have safety problem. Further, the durability has seriously decreased. The bridge can be continued in use only if the bridge receives extensive repairs or the load capacity is reduced.

Grade IV: The external look of the bridge or its members has severe damage. The member rigidity and bearing capacity are unserviceable. The reliability is also very bad. The rate of fracture due to damage is very fast. The bridge should be taken out of use.

The damage evaluation for a bridge is a kind of fuzzy process. Since bridges are built of many members, the influence of every member is very complex. For instance, the factors of strength, deformation, crack and steel corrosion are pivotal points for the integrity evaluation of a bridge. During the evaluation process, the interaction and influence among these factors will result in the overall evaluation. Therefore, the evaluation of a bridge, one utilizes the synthesis of a double-layer fuzzy process to determine the influence among these factors. 


\section{Theory of Analytical Model}

Based on the theory of fuzzy mathematics for performancing synthesis evaluation, one establishes herein the analytical model for the damage evaluation of a bridge. The theory of analytical model of fuzzy mathematics is described in the following:

Assume that the comment domain of the evaluation factor is $U=\left\{u_{1}, u_{2}, \ldots, u_{n}\right\}$, where $u_{i}$ represents the factor for evaluation, in which $i=1,2,3, \ldots, n$. The domain of the evaluation grade is $V=\left\{v_{1}, v_{2}, \ldots, v_{n}\right\}$, where $v_{i}$ expresses the evaluation results of the damage degree obtained from every considered factor, in which $j=1,2,3, \ldots, m$. In order to consider the influences of interaction among the evaluation factors, one adopts the weighting concept for performing the synthesis evaluation on every factor. Hence, one introduces the fuzzy set of weighting factors $A=\left(a_{1}, a_{2}, \ldots, a_{n}\right)$, where $a_{i}$ indicates the corresponding weight of the $i$-th factor $u_{i}$. The fuzzy set A is also satisfied

$$
\sum_{i=1}^{n} a_{i}=1 \text {. }
$$

However, for a fuzzy evaluation with a single factor to the $i$-th factor, one fuzzy subset is used on the domain of evaluation grade $\mathrm{V}$

$$
R_{i}=\left(r_{i 1}, r_{i 2} \ldots \ldots . r_{i m}\right),
$$

where $r_{i m}$ denotes the evaluation value of the $i$-th evaluation factor to the membership degree of the $m$-th evaluation grade. When every factor introduces an evaluation state, one can establish the total evaluation matrix

$$
R=\left[\begin{array}{c}
R_{1} \\
R_{2} \\
\vdots \\
R_{n}
\end{array}\right]=\left[\begin{array}{cccc}
r_{11} & r_{12} & \cdots & r_{1 m} \\
r_{21} & r_{22} & \cdots & r_{2 m} \\
\vdots & \vdots & \ddots & \vdots \\
r_{n 1} & r_{n 2} & \cdots & r_{n m}
\end{array}\right]
$$

Employing the fuzzy synthesis evaluation, the fuzzy synthesis evaluation to every factor can be set up

$$
B=A \cdot R .
$$

It is worth to point out that Eq. (4) belongs to the fuzzy mathematics operational method. The fuzzy mathematics operational technique is quite different from the matrix product operational approach in general mathematics. In fuzzy mathematics, the rule of matrix product iusually take the minimum value and then select the maximum value. For instance, given $A=$ $\left[\begin{array}{lll}0.2 & 0.7 & 0.32\end{array}\right]$ and

$$
R=\left[\begin{array}{cc}
0.21 & 0.12 \\
0.87 & 0.75 \\
0.23 & 0.9
\end{array}\right]
$$

Then

$$
\begin{aligned}
B= & A \cdot R=\left[\begin{array}{lll}
0.2 & 0.7 & 0.32
\end{array}\right] \bullet\left[\begin{array}{cc}
0.21 & 0.12 \\
0.87 & 0.75 \\
0.23 & 0.9
\end{array}\right] \\
= & {[(0.2 \wedge 0.21) \vee(0.7 \wedge 0.87) \vee(0.32 \wedge 0.23)} \\
& (0.2 \wedge 0.12) \vee(0.7 \wedge 0.75) \vee(0.32 \wedge 0.9)] \\
= & {\left[\begin{array}{ll}
0.2 \vee 0.7 \vee 0.23 & 0.12 \vee 0.7 \vee 0.32
\end{array}\right] } \\
= & {\left[\begin{array}{ll}
0.7 & 0.7
\end{array}\right] . }
\end{aligned}
$$

In the example mentioned earlier, the element $B$ in Eq. (4) can be written as

$$
B_{i j}=\max \min \left[a_{i k}, r_{k j}\right]=\vee_{i}\left[a_{i k} \wedge r_{k j}\right],
$$

where $\vee$ represents that one takes the relative maximum value, i.e., $a \vee r=\max \left(a_{i}, r_{i}\right)$, and $\wedge$ indicates that one select the relative minimum value, i.e., $a \wedge r=\min \left(a_{i}\right.$, $\left.r_{i}\right)$.

In the evaluation of damage in existing bridges, because the bridge members are considerablely complicted, many factors should be considered. Therefore, one has to adopt the fuzzy evaluation approach to evaluate the damage in existing bridges. As mentioned above, in the numerous members of bridge, one must consider the beams, columns, decks and piles which influence the damage to the entire structure. Every-type of member can be referred as an integrity evaluation factor. The damage to every member is determined by the influence of the other factors. Therefore, the damage evaluation of bridge is an analytical problem of double-layer synthesis evaluation. One now carries out the double-layer synthesis fuzzy evaluation method based on the evaluation technique previously mentioned:

First: Let the comment domain of evaluation factor divide into $K$ subset according to any attribute, i. e., $U_{1}, U_{2}, \ldots, U_{k}$. And let them satisfy

$$
\bigcup_{i=1}^{k} U_{i}=U, U i U j=f(i \neq j) \text {, }
$$

where every subset $U_{i}=\left\{u_{i 1}, u_{i 2}, \ldots, u_{i n}\right\}$,

$$
\sum_{i=1}^{k} n_{i}=n
$$

Second: For the relative performance synthesis evaluation, assume that the corresponding factor weighting set is $A_{i}$, the evaluation matrix of any single factor is $R_{i}$, then the evaluation set is 


$$
B_{i}=A_{i} \cdot R_{i}=\left(b_{i 1}, b_{i 2} \ldots \ldots b_{i m}\right),
$$

where $i=1,2,3, \ldots, k$.

Third: Let every $U_{i}$ represent a factor and $B_{i}$ as its single factor evaluation, then the single factor evaluation matrix of $\left\{U_{1}, U_{2} \ldots, U_{k}\right\}$ is

$$
R=\left[\begin{array}{c}
B_{1} \\
\vdots \\
B_{i} \\
\vdots \\
B_{k}
\end{array}\right] .
$$

After establishing the factor evaluation matrix, one can understand that every subset for each member would be respond to some attributes. In order to distinguish the important degree of reliability of the whole structure to each factor, one should redistribute the weight. Hence, given the new weighting set $A_{\text {new }}$, the final evaluation equation is

$$
B=A_{\text {new }} \cdot R
$$

For the practical damage bridge analysis, one will apply the theory to the practical engineering problem. However, before introducing the practical problem, in order to deeply understand the details for the researcher and specialist, the trifles are described in the following.

Based on the theory stated above, the whole bridge members were divided into each factor set. For instance, one partitions the entire bridge into the subsets of deck, superstructure, and substructure. These subsets concentrate as a factor set $U$ and also satisfy Eqs. (6) and (7).

When the fuzzy analysis for practical problem is performed, one usually performs a single-layer synthesis evaluation for every-type of member. The influence factors are described in the following:

[1] outward appearance

General external appearance, extent of any external damage and the serviceability of existing bridges should be inspected in the field.

[2] cracks

Based on the field survey, one must evaluate the influence and safety of each member due to cracks in existing bridges.

[3] steel corrosion

Based on the field survey, estimate spalled concrete and the state of decreased cross-sectional steel area due to steel corrosion.

In the practical evaluation, one finds that the influence of these factors is not as important as predicted. For instance, one originally regards that the deflection and strength of each member will result in decreased safety in the existing bridge. In fact, not only deflection but also strength is generally satisfied by the specification requirements in the design. Therefore, in order to simplify the evaluation process, factors such as deflection, strength and so on are neglected in the evaluation method. Based on the classification stated above, the relationship between the evaluation factors in existing bridges are shown in Fig. 1. The contents of the relationship, as shown in Fig. 1, is a kind of expansible relationship. One can change the contents according to the different requirements for different bridges. To clearly provide the standard influence factor of $U_{i}$, the evaluation grade a, b, c and d of outward appearance, cracks, and steel corrosion are listed in Tables 1 to 3 , respectively. For the comment domain of evaluation grade $V$, one represents

$$
V=\left\{V_{1}, V_{2}, V_{3}, V_{4}\right\},
$$

where $V_{1}, V_{2}, V_{3}$, and $V_{4}$ are expressed as Grade I, II, III, and IV mentioned above, respectively.

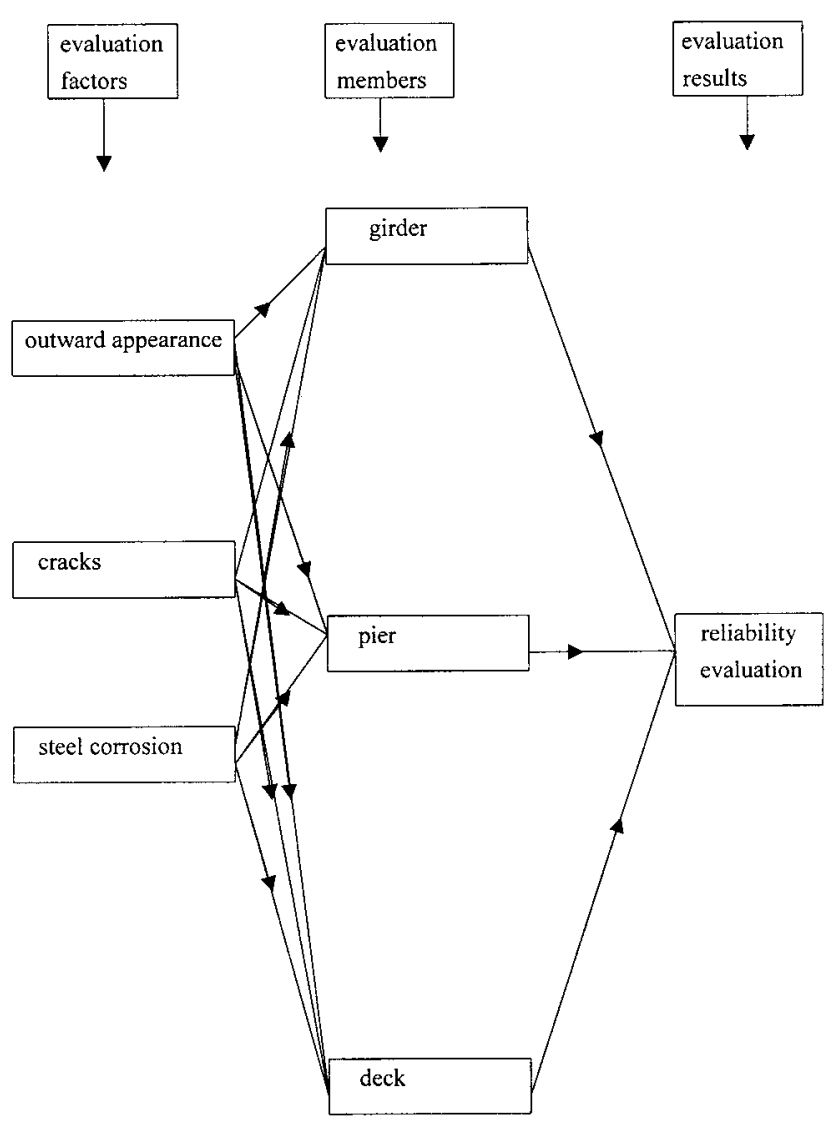

Fig. 1. Relationship of evaluation factors. 
Table 1. Evaluation grade of member outward appearance

\begin{tabular}{|c|c|c|c|c|}
\hline $\begin{array}{c}\text { Evaluation } \\
\text { grade }\end{array}$ & $\mathrm{a}$ & $\mathrm{b}$ & $\mathrm{c}$ & $\mathrm{d}$ \\
\hline Description & $\begin{array}{l}\text { External look is } \\
\text { perfect without any } \\
\text { damage. }\end{array}$ & $\begin{array}{l}\text { External look has some } \\
\text { pock-warked faces with } \\
\text { honeycomb due to bad } \\
\text { construction and has ap- } \\
\text { peared some steels oc- } \\
\text { curred concrete spall. }\end{array}$ & $\begin{array}{l}\text { External look has ap- } \\
\text { peared some steels with } \\
\text { width } 0.25 \sim 0.50 \mathrm{~mm}\end{array}$ & $\begin{array}{l}\text { External look has appeared } \\
\text { some steels above width } \\
0.5 \mathrm{~mm} \text { and concrete spall. }\end{array}$ \\
\hline
\end{tabular}

\section{ILLUSTRATIVE EXAMPLES}

The methods and principles of single- and doublelayer synthesis evaluation have been described. Now one applys these theories to practical engineering cases. One also uses this proposed method herein to lead civil engineers to understand this system for evaluating the damage state of existing bridges.

In order to verify this proposed method, four existing RC bridges in Taipei were used for serviceability evaluation. These four RC bridges are the Huey-tong bridge, the Jzyh-chyang bridge, the Ay-gwo west road viaduct, and the old Hwan-nan viaduct. The overall structural conditions are listed in Tables 4-7, respectively.

Tables 8 and 9 show the supportability and antiseismic ability preliminary evaluation of the Huey-tong bridge. The other bridge also received the same preliminary evaluation. After understanding the overall structural conditions, one can carry out the evaluation analysis. First, according to Fig. 1, both the evaluation factors and grade set of these four existing RC bridges are listed in Tables 10-13. Based on the Tables 10-13, the single-layer synthesis evaluation is first analyzed and then the double-layer synthesis is performed in order to attain the evaluation degree. The Huey-tong bridge was used for a practical example to perform deep analysis. The evaluation results of the other bridges can obtained by the same analytical way. The Huey-tong bridge is evaluated in the following.

\section{1. single-layer synthesis evaluation for member}

[1]. Establish firmly the influence factor of member during evaluation and determine the weight of every factor. Since the influence factor of every member has its different proportion, the weight allocations for every member are not the same. Now one divides the bridge considered into three members, i.e., girder, pier, and deck. For girder, pier, and deck, the weight allocations of influence factors of outward appearance, cracks, and steel corrosion are 0.81 . 0 , and 1.0, respectively. Nor-
Table 2. Evaluation grade of cracked width for the members of reinforced concrete

\begin{tabular}{ccccc}
\hline $\begin{array}{c}\text { Evaluation } \\
\text { grade }\end{array}$ & $\mathrm{a}$ & $\mathrm{b}$ & $\mathrm{c}$ & $\mathrm{d}$ \\
\hline $\begin{array}{c}\text { Cracked width } \\
(\mathrm{mm})\end{array}$ & $\leq 0.2$ & $\leq 0.35$ & $\leq 0.4$ & $>0.4$ \\
\hline
\end{tabular}

Table 3. Evaluation grade of steel corrosion

\begin{tabular}{ccccc}
\hline $\begin{array}{c}\text { Evaluation } \\
\text { grade }\end{array}$ & a & b & c & d \\
\hline$\frac{A^{*}}{A_{0}}$ & 0 & $\leq \frac{\mathbf{1}}{\mathbf{6}}$ & $\leq \frac{\mathbf{1}}{\mathbf{3}}$ & $>\frac{\mathbf{1}}{\mathbf{3}}$ \\
\hline
\end{tabular}

*: $A_{0}$-originally cross-sectional area of steel; A-cross-sectional area of steel after corrosion.

malized the weight allocation, from Eq. (1),one obtains $\sum_{i=1}^{n} a_{i}=0.8+1.0+1.0=2.8$. Through transformation the outward appearance, cracks, and steel corrosion have the values of $0.286,0.357$, and 0.357 , respectively. With regard to expansion joint, the weight allocation of influence factors of outward appearance, cracks, and steel corrosion are $0.9,0$, and 1.0 , respectively. After transformation, one obtains that outward appearance, cracks and steel corrosion have the values of $0.474,0$, and 0.526 , respectively. Based on the previous theory, $A_{1}$ is used to express the weight set of girder and gets $A_{1}$ $=[0.286,0.357,0.357]$. Similarly, let $A_{2}$ and $A_{3}$ be the weight sets of pier and deck, $A_{2}=A_{3}=[0.286,0.357$, $0.357]$.

[2]. Carry out synthesis evaluation for each member

a. synthesis evaluation of girder

Since the evaluation matrix and weight set are, respectively,

$$
R_{1}=\left[\begin{array}{cccc}
0.62 & 0.2 & 0.15 & 0.03 \\
0.6 & 0.2 & 0.15 & 0.05 \\
0.7 & 0.15 & 0.1 & 0.05
\end{array}\right] \text { and } A_{1}=[0.286
$$


Table 4. Overall structural conditions of the Huey-tong bridge

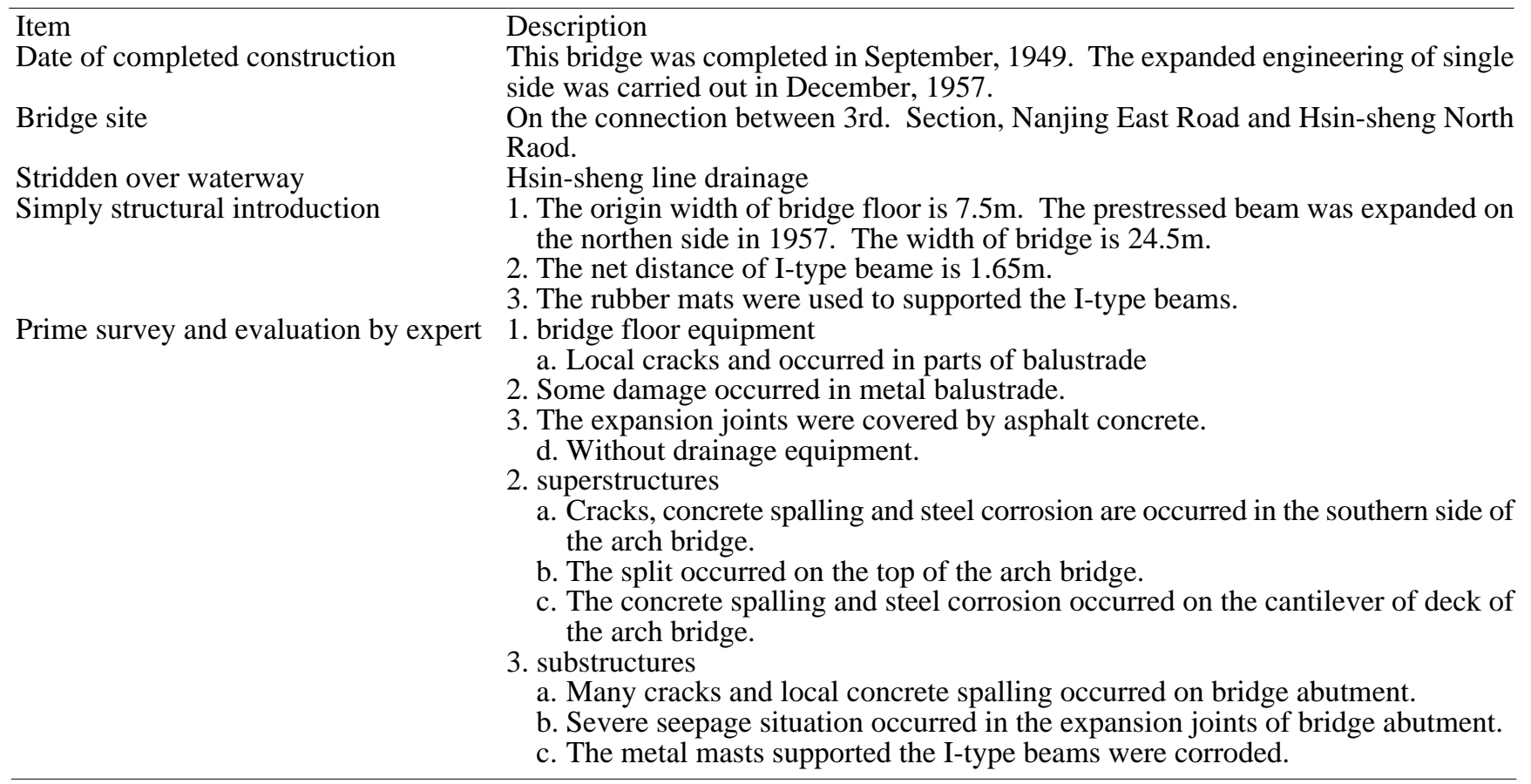

Table 5. Overall structural conditions of the Jzyh-chyang bridge

Item
Date of completed construction
Bridge site
Stridden over waterway
Simply structural introduction

Prime survey and evaluation by expert
Description

This bridge was completed in 1972 .

Connect the Jzyh-chyang tunnel at the Shyh-lin exit with Guh-gong road.

The Way-shuang stream

1. The bridge floor was planned as one way for vehicular traffic and sidewalk. The width to bridge deck is $10.2 \mathrm{~m}$.

2. The superstructures is two straddling $(33 \mathrm{~m}-33 \mathrm{~m})$ of simply supported prestressed I-type beam.

3. The pier of substructures are doorframe types.

4. The cast steel socket was used for support.

5. The kind of expansion joint was made from steel.

1. bridge floor equipment

a. Local concrete spalling occurred on balustrade. Local damage of aluminium balustrade was happen.

b. Some expansion joints were damaged or were covered by asphalt concrete.

c. Local pavement with asphalt concrete is not steady and smooth. It easily influences the comfort movement of vehicles.

d. The concrete on sidewalk in east line has local spalling.

e. The drain weeps were set up for drain tile. The drain water directly flow down along girders.

2. superstructures

a. A part of prestressed beam have concrete spalling and honeycomb situations.

b. Both bridge deck and separated beam have local concrete spalling, honeycomb, and steel corrosion situations.

3. substructures

a. Column supported piers have local concrete spalling, steel corrosion and cracks.

b. The hinges made with steel for support girder are severely corroded.

c. The capbeams in east line have local concrete spalling and steel exposuse situation while the capbeams in west line also have severe concrete spalling, steel exposure and cracks situations.

d. Concrete remnants due to replaced expansion joint were discovered on the top of bridge abutment and capbeam. 
Table 6. Overall structural conditions of the Ay-gwo west road viaduct

\begin{tabular}{ll}
\hline Item & $\begin{array}{l}\text { Description } \\
\text { Date of completed construction } \\
\text { Viaduct site }\end{array}$ \\
$\begin{array}{l}\text { This viaduct was completed in } 1983 . \\
\text { Locates on the Ay-gwo west road. Strides over Yan-pyng south road and the circle } \\
\text { of Jong-haw road. Fork at Jong-haw road and connect to Guey-lin road Nor-ling road. } \\
\text { Thi viaduct strides over Yan-pyn south road and the circle of Jong-haw road. } \\
\text { Simply structural introduction }\end{array}$ & $\begin{array}{l}\text { 1. bridge deck: a. connected Ay-gwo west road with } 22.1 \mathrm{~m} ; \\
\text { b. connected Nan-Ning road with } 16.1 \mathrm{~m} ;\end{array}$ \\
c. conncected Guey-lin road with $8.1 \mathrm{~m}$ width.
\end{tabular}

2. structural type:a. two or three straddling of continuounsly prestressed box beam; b. composite box steel for simple support.

3. Substructures are made of concrete: a. piers consist of three columns; b. Doorframe piers composed two to four columns.

4. The bridge abutment is a kind of cantilever type.

5. Foundation type: a. prestressed concrete pile; b. steel-pipe pile; c. reverse circulation pile.

6. Supported type: a. rubber support; b. steel support.

7. The expansion joint is modular type.

Prime sruvey and evaluation by expert 1 . bridge floor equipment

a. The breast walls of all lines have steel corrosion, and concrete spalling.

b. The expansion joints of bridge floor have seepage. The substructures suffered long-term erosion.

c. The drain weeps of guide way were widespread blocked.

2. superstructures

a. The bottoms of prestressed box beam have not enough concrete covering and have local concrete spalling. Beam bottom near capbeam has many cracks.

b. The steel beam stridden over Jong-hwa road have severe corrosion due to seepage from upper expansion joints and joints.

c. The bridge floor of concrete box beam has concrete spalling cracks, and specks.

3. substructures

a. The top of pier without capbeam has obvious cracks.

b. The expansion joints of bridge floor have severe seepage. This is easily occurred a mass on the top of capbeam and the corrosion of supported steel.

c. The capbeams all have cracks and local concrete spalling and steel exposure.

0.357, 0.357], one obtains from Eq. (4)

$$
\begin{aligned}
& B_{1}=A_{2} \cdot R_{1}=\left[\begin{array}{lll}
0.268 & 0.357 & 0.357
\end{array}\right] \\
& {\left[\begin{array}{cccc}
0.62 & 0.2 & 0.15 & 0.03 \\
0.6 & 0.2 & 0.15 & 0.05 \\
0.7 & 0.15 & 0.1 & 0.05
\end{array}\right]=\left[\begin{array}{llll}
0.357 & 0.2 & 0.15 & 0.05
\end{array}\right]}
\end{aligned}
$$

After normalizing to $B_{1}$ has $B_{1}=\left[\begin{array}{ll}0.472 & 0.264\end{array}\right.$ $0.1980 .066]$.

b. synthesis evaluation of pier

Because the evaluation matrix and weight set are, respectively,

$R_{2}=\left[\begin{array}{cccc}0.7 & 0.15 & 0.08 & 0.07 \\ 0.5 & 0.2 & 0.15 & 0.15 \\ 0.6 & 0.2 & 0.17 & 0.03\end{array}\right]$ and $A_{2}=[0.286,0.357$,

0.357], from Eq. (4)

$$
\begin{aligned}
& B_{2}=A_{2} \bullet R_{2}=\left[\begin{array}{lll}
0.268 & 0.357 & 0.357
\end{array}\right] \\
& {\left[\begin{array}{cccc}
0.7 & 0.15 & 0.08 & 0.07 \\
0.5 & 0.2 & 0.15 & 0.15 \\
0.6 & 0.2 & 0.17 & 0.03
\end{array}\right]=\left[\begin{array}{llll}
0.357 & 0.2 & 0.17 & 0.15
\end{array}\right]}
\end{aligned}
$$

Normalization to $B_{2}$ leads $B_{2}=\left[\begin{array}{lll}0.402 & 0.225 & 0.192\end{array}\right.$ $0.181]$.

c. synthesis evaluation of deck

Since the evaluation matrix and weight set are, respectively, $R_{3}=\left[\begin{array}{cccc}0.8 & 0.2 & 0 & 0 \\ 0.9 & 0.1 & 0 & 0 \\ 0.98 & 0.02 & 0 & 0\end{array}\right]$ and $A_{3}=[0.286$, 0.357, 0.357], from Eq. (4)

$$
\begin{aligned}
B_{3} & =A_{3} \cdot R_{3}=\left[\begin{array}{lll}
0.268 & 0.357 & 0.357
\end{array}\right]\left[\begin{array}{cccc}
0.8 & 0.2 & 0 & 0 \\
0.9 & 0.1 & 0 & 0 \\
0.98 & 0.02 & 0 & 0
\end{array}\right] \\
& =\left[\begin{array}{llll}
0.357 & 0.2 & 0 & 0
\end{array}\right] .
\end{aligned}
$$


Table 7. Overall structural conditions of the old Hwan-nan viaduct

Item

Date of completed construction

Viaduct site

Stridden over junction viaduct Simply structural introduction

\section{Description}

This viaduct was complated in 1974. The replaced engineering was completed in 1988.

Local on Hwan-her south road. This road surface is northern from Jong-shiaw west road and southern to Guey-lin road.

viaduct

1. Bridge width is $7 \mathrm{~m}$.

2. Superstructures: a. Box beam with nonequilibrium cantilever plate. b. Densely arrange the rectangular hollow made from precast prestressed concrete. c. Closely arrange I-type beam made from precast prestressed concrete. d. Hollow platebeam made from field cast concrete. e. Solid plate-beam made from field cast concrete.

3. Substructures: a. Single-column pier, b. camp pier.

4. Supported type: a. rubber mats for support, b. steel mats for support, c. connected with column.

Prime survey and evaluation by expert 1 . bridge floor equipment

a. All line rails have damage, steel corrosion and concrete spalling. The breast walls of the outside carriage way have obviously not enough concrete covering induced steel exposure.

b. The seepage of all line expansion joints result from a mass on the top of capbeam and corrosion at supported steel plate. The expansion joints of parts of road section were covered by asphalt concrete and were loss function.

c. The pavements of all line asphalt concrete are damaged and have accumulated water.

d. The drain weeps of guide way were spread widely blocked and were loss function

e. A part of stair has concrete spalling and steel exposure and corrosion.

2. superstructures

a. The outside bottom of bridge floor of old viaduct have not enough cover thickness of steel.

b. Bottom of parts girder have concrete spalling and steel exposure and corrosion. 3. substructures

a. Column supported pier and capbeam of old viaduct have obviously cracks, seepage, and white specks phenomena.

b. A large mass was located on the top of capbeam. This is easily occurred a degenerate of rubber mats.
After normalizing to $B_{3}$ has $B_{3}=\left[\begin{array}{llll}0.64 & 0.36 & 0 & 0\end{array}\right]$.

\section{Double-layer synthesis evaluation for bridge}

The single member damage evaluation due to each evaluation factor has been described as mentioned before. Now every member is combined for carrying out the entire synthesis evaluation. As described above, the weight distribution to every member is executed based on expert survey method. Because bridge damage usually occurs in superstructures (cracks in deck and capbeam) and substructures (pier and pile failure), one will concentrate the whole evaluation of each bridge member on the superstructures and substractures. For this reason, one performances the ratio of weight alloca- tion for girder, pier, and deck as 1.0, 1.0 and 0.9, respectively. Normalization to the weight set mentioned early yields $A=\left[\begin{array}{lll}0.345 & 0.345 & 0.31\end{array}\right]$. From Eq. (3), one obtains the total evaluation matrix

$$
R=\left[\begin{array}{l}
B_{1} \\
B_{2} \\
B_{3}
\end{array}\right]=\left[\begin{array}{cccc}
0.472 & 0.264 & 0.198 & 0.066 \\
0.402 & 0.225 & 0.192 & 0.181 \\
0.64 & 0.36 & 0 & 0
\end{array}\right]
$$

Through Eq. (4) one has $B=A \cdot R=\left[\begin{array}{ll}0.345 & 0.345\end{array}\right.$

$$
\begin{gathered}
0.31]\left[\begin{array}{cccc}
0.472 & 0.264 & 0.198 & 0.066 \\
0.402 & 0.225 & 0.192 & 0.181 \\
0.64 & 0.36 & 0 & 0
\end{array}\right] \\
=\left[\begin{array}{llll}
0.345 & 0.32 & 0.198 & 0.181
\end{array}\right] .
\end{gathered}
$$




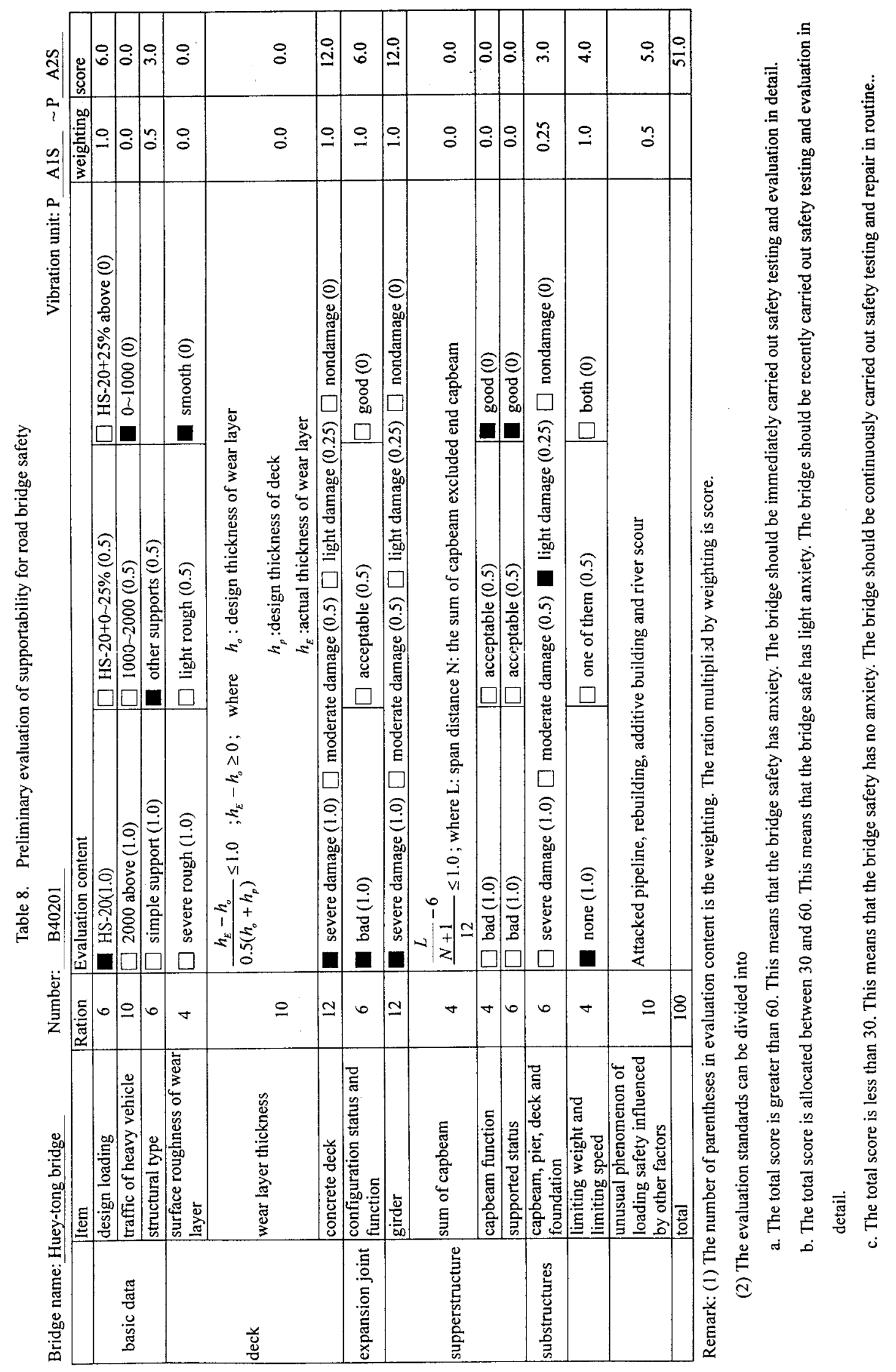


Table 9. Preliminary evaluation of anti-seismic ability for road bridge safety

Bridge name: Huey-tong bridge $\quad$ Number: $\quad$ B40101 Vibration unit: P_A1S $\sim$ P A2S

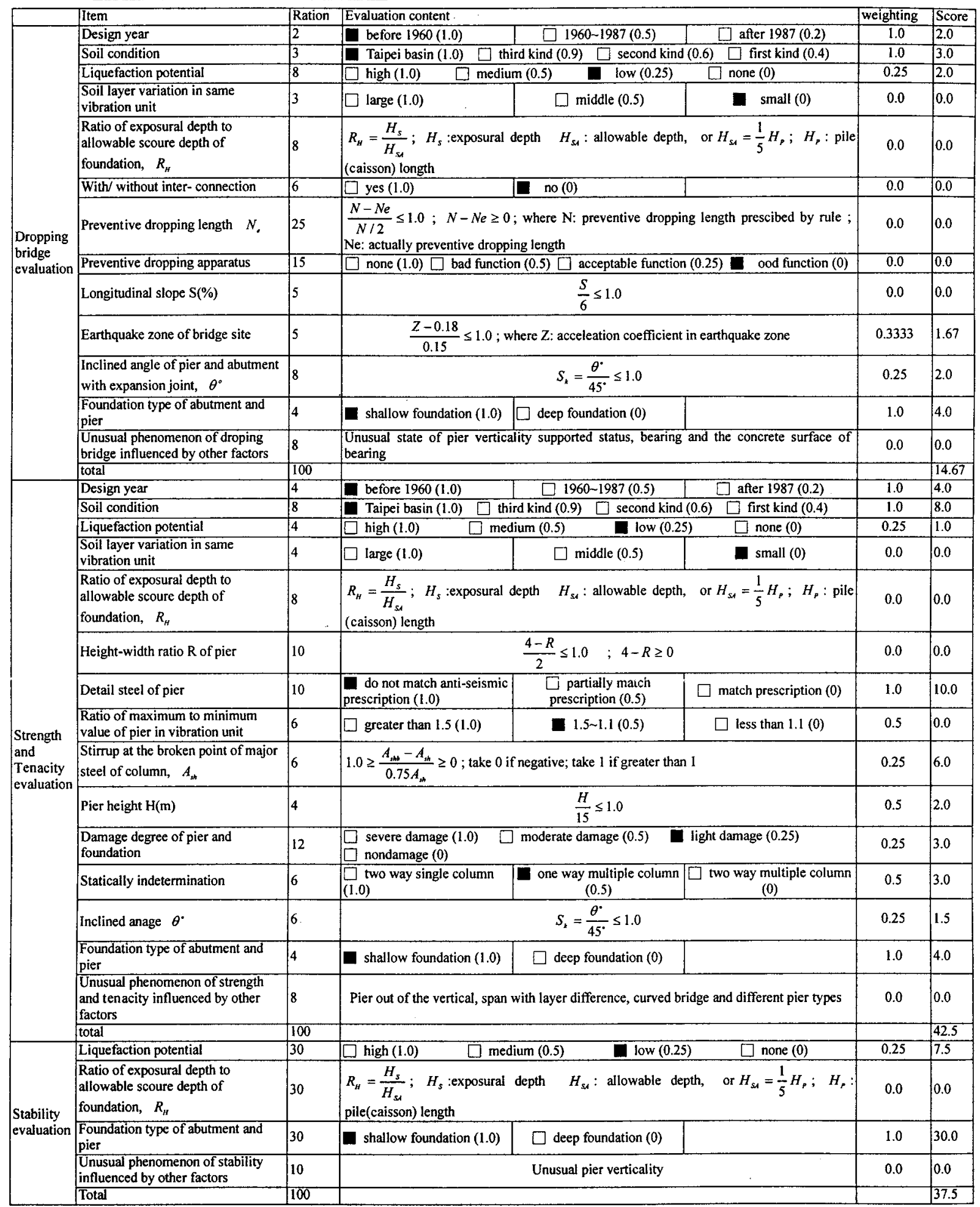

Remark: (1) and (2) are the same as (1) and (2) in Table 8, respectively.

(3) $\mathrm{N}=50+0.25 \mathrm{~L}+1.0 \mathrm{H}$; where $\mathrm{L}$ is span distance $(\mathrm{m}), \mathrm{H}$ is the height of substructure $(\mathrm{m})$, the unit of $\mathrm{N}$ is $\mathrm{cm}$.

(4) Soil condition can be found in reference "Taiwan Construction Research Institute"

(5) $A_{\star b}$ is the stirnup of column at bottom. 
Table 10. Evaluation factors and membership degree of the Huey-tong bridge

\begin{tabular}{llcccc}
\hline \multirow{2}{*}{$\begin{array}{l}\text { Member } \\
\text { classification }\end{array}$} & Evaluation factors & $\mathrm{V}_{1}$ & $\mathrm{~V}_{2}$ & $\mathrm{~V}_{3}$ & $\mathrm{~V}_{4}$ \\
\cline { 2 - 6 } \multirow{*}{*}{ Girder } & Outward & 0.62 & 0.2 & 0.15 & 0.03 \\
& $\begin{array}{l}\text { appearance } \\
\text { Cracks }\end{array}$ & 0.6 & 0.2 & 0.15 & 0.05 \\
& Steel corrosion & 0.7 & 0.15 & 0.1 & 0.05 \\
\hline \multirow{3}{*}{ Pier } & Outward & 0.7 & 0.15 & 0.08 & 0.07 \\
& appearance & & & 0.15 & 0.15 \\
& Cracks & 0.6 & 0.2 & 0.17 & 0.03 \\
& Steel corrosion & 0.6 & 0.2 & 0 & 0 \\
\multirow{3}{*}{ Deck } & Outward & 0.8 & 0.2 & 0 & 0 \\
& appearance & & & 0 \\
\hline
\end{tabular}

Table 11. Evaluation factors and membership degree of the Jzyh-chyang bridge

\begin{tabular}{llcccc}
\hline \multirow{2}{*}{$\begin{array}{l}\text { Member } \\
\text { classification }\end{array}$} & \multicolumn{4}{c}{ Membership degree } \\
\cline { 2 - 5 } & Evaluation factors & $\mathrm{V}_{1}$ & $\mathrm{~V}_{2}$ & $\mathrm{~V}_{3}$ & $\mathrm{~V}_{4}$ \\
\hline \multirow{3}{*}{ Girder } & Outward & 0.8 & 0.1 & 0.07 & 0.03 \\
& appearance & & & 0 & 0 \\
& Cracks & 0.9 & 0.1 & 0 & 0 \\
\hline \multirow{3}{*}{ Pier } & Steel corrosion & 0.9 & 0.1 & 0.07 & 0.03 \\
& Outward & 0.7 & 0.2 & 0.1 & 0.05 \\
& appearance & & & 0 & 0 \\
& Cracks & 0.7 & 0.15 & 0 & 0 \\
\multirow{3}{*}{ Deck } & Steel corrosion & 0.9 & 0.1 & & 0.03 \\
& Outward & 0.9 & 0.1 & 0.07 & 0 \\
\hline & appearance & & & 0.02 & 0 \\
\hline
\end{tabular}

After executing normalization for $B$, one gets $B=$ $\left[\begin{array}{llll}0.334 & 0.30 & 0.191 & 0.175\end{array}\right]$. This is the evaluation results of the Huey-tong bridge. The investigated results indicate that the structural properties belong to Grade I, II, III, and IV which have membership value of 0.334 , $0.300,0.191$ and 0.175 , respectively. This result is listed in Table 14. Looking at the matter from this viewpoint, the damage to the Huey-tong bridge is below middle damage. Therefore, small repairs are necessary for the Huey-tong bridge. With respect to the Jzyhchyang bridge, the Ay-gwo west road viaduct, and the old Hwan-nan viaduct, the evaluation results using the same analytical process as the Huey-tong bridge. These evaluation results are in Table 14. From Table 14, one can see that the Jzyh-chyang bridge is Grade I, II, III, and IV with $0.410,0.337,0.168$, and 0.085 , respectively. The structural properties of the Ay-gwo west road viaduct were attributed to Grade I, II, III, and IV which have the membership value of $0.363,0.326,0.193$ and 0 . 118, respectively. The old Hwan-nan viaduct was the properties of Grade I, II, III, and IV with 0.354, 0.354, 0.198 , and 0.094 , respectively.

\section{DISCUSSION}

The concept of fuzzy mathematics was adopted to establish the double layer fuzzy synthesis evaluation method for existing RC bridges. With the aid of the proposed double layer fuzzy analysis method, the evaluated bridge damage results will increase the objectivity and integrity. Because the reasons for the bridge dam- 
Table 12. Evaluation factors and membership degree of the Ay-gwo west road viaduct

\begin{tabular}{llcccc}
\hline \multirow{2}{*}{$\begin{array}{l}\text { Member } \\
\text { classification }\end{array}$} & Evaluation factors & $\mathrm{V}_{1}$ & $\mathrm{~V}_{2}$ & $\mathrm{~V}_{3}$ & $\mathrm{~V}_{4}$ \\
\cline { 2 - 6 } \multirow{3}{*}{ Girder } & Outward & 0.6 & 0.2 & 0.11 & 0.09 \\
& $\begin{array}{l}\text { appearance } \\
\text { Cracks }\end{array}$ & 0.6 & 0.25 & 0.1 & 0.05 \\
& Steel corrosion & 0.7 & 0.21 & 0.09 & 0 \\
\hline \multirow{3}{*}{ Pier } & Outward & 0.7 & 0.2 & 0.1 & 0 \\
& appearance & & & 0.11 & 0.09 \\
& Cracks & 0.5 & 0.3 & 0.05 & 0 \\
\hline \multirow{5}{*}{ Deck } & Steel corrosion & 0.8 & 0.15 & 0.05 & 0 \\
& Outward & 0.8 & 0.15 & & 0.03 \\
& appearance & & & 0.12 & 0.03 \\
\hline & Cracks & 0.7 & 0.15 & 0.12 & \\
\hline
\end{tabular}

Table 13. Evaluation factors and membership degree of the Hwan-nan viaduct

\begin{tabular}{llcccc}
\hline \multirow{2}{*}{$\begin{array}{l}\text { Member } \\
\text { classification }\end{array}$} & Evaluation factors & $\mathrm{V}_{1}$ & $\mathrm{~V}_{2}$ & $\mathrm{~V}_{3}$ & $\mathrm{~V}_{4}$ \\
\cline { 2 - 5 } \multirow{3}{*}{ Girder } & Outward & 0.7 & 0.2 & 0.1 & 0 \\
& $\begin{array}{l}\text { appearance } \\
\text { Cracks }\end{array}$ & 0.7 & 0.18 & 0.1 & 0.02 \\
& Steel corrosion & 0.7 & 0.2 & 0.1 & 0 \\
\hline \multirow{3}{*}{ Pier } & Outward & 0.7 & 0.13 & 0.1 & 0.07 \\
& appearance & & & 0.15 & 0.05 \\
& Cracks & 0.6 & 0.2 & 0.1 & 0 \\
\hline \multirow{3}{*}{ Deck } & Steel corrosion & 0.7 & 0.2 & 0.1 & 0 \\
& Outward & 0.7 & 0.2 & 0.1 & 0.05 \\
& appearance & & & 0 & 0 \\
\hline
\end{tabular}

age are evaluated in more detail, both the damage item of every member and the weight function of every item are thus established. As a result, the double layer guarantee will increase the evaluated reliability in depth. With the view of establishing an evaluation system method which is suitable for practice and usage, four existing RC bridges in Taipei were adopted as illustrative examples. In order to enhance the proposed method which involves not only serviceability but also reliability, the method of the Taiwan Construction Research Institute (1996) was applied to calculating the four bridges and are listed in Table 14. From Table 14, it is found that either the supportability or anti-seismic ability of the Huey-tong bridge obtained from the Taiwan Construction Research Institute were needed to carry out detailed inspection and reinforcement for some members.
In the results predicted by the proposed method, it was also revealed that the membership of grade IV of the Huey-tong bridge is 0.175 . This means that the Hueytong bridge has light damage. However, it can be continuously used if small scale repairs or reinforcement are performed.

As in the illustration and verification of the Hueytong bridge, similar results for the Jzyh-chyang bridge, Ay-gwo west road viaduct and old Hwan-nan viaduct were obtained and are listed in Table 14. In view of the grade IV for the four bridges in Table 14, the order of repair and reinforcement is the Huey-tong bridge, Aygwo west road viaduct, old Hwan-nan viaduct and Jzyhchyang bridge. Through this investigation, it is worth to point out that the proposed method is not only serviceable but also reliable. 
Table 14. Comparison of proposed method and Taiwan Construction Research Institute results of damage evaluation for four bridges in Taipei

\begin{tabular}{|c|c|c|}
\hline bridge name evaluation method & Method of Jwu et al. [1991] & $\begin{array}{l}\text { Method of Taiwan Construction } \\
\text { Research Institute }^{+}\end{array}$ \\
\hline Huey-tong bridge & $\begin{array}{l}\text { I: } 0.334 \\
\text { II: } 0.300 \\
\text { III: } 0.191 \\
\text { IV: } 0.175\end{array}$ & $\begin{array}{l}\text { Supportability: 51 36 } \\
\text { Anti-seismic ability: 40 44 }\end{array}$ \\
\hline Jzyh-chyang bridge & $\begin{array}{l}\text { I: } 0.410 \\
\text { II: } 0.337 \\
\text { III: } 0.168 \\
\text { III: } 0.085\end{array}$ & $\begin{array}{l}\text { Supportability: 31 26 } \\
\text { Anti-seismic ability: } 35 \sim 48\end{array}$ \\
\hline Ay-gwo west road viaduct & $\begin{array}{l}\text { I: } 0.636 \\
\text { II: } 0.326 \\
\text { III: } 0.193 \\
\text { IV: } 0.118\end{array}$ & $\begin{array}{l}\text { Supportability: } 35 \sim 42 \\
\text { Anti-seismic ability: } 28 \sim 45\end{array}$ \\
\hline old Hwan-nan viaduct & $\begin{array}{l}\text { I: } 0.354 \\
\text { II: } 0.354 \\
\text { III: } 0.198 \\
\text { IV: } 0.094\end{array}$ & $\begin{array}{l}\text { Supportability: 302 42 } \\
\text { Anti-seismic ability: 39 23 }\end{array}$ \\
\hline
\end{tabular}

+: The evaluation grade of Taiwan Construction Research Institute:

a. When mark is greater than 60 , bridge has some problems of safety. It is needed to perform safe inspection and evaluation in detail.

b. When mark is greater than 30 but less than 60, bridge is of little safe problem.

It should recently be carried out safe inspection and evaluation in detail. When mark is less than 30, bridge has no safe problem. However, it is necessarily continued to do the usual inspection and repair.

\section{CONCLUSIONS}

The fuzzy mathematics with single- and doublelayer synthesis evaluation methods have been described. This proposed method was applied to four existing RC bridges in Taipei. The results of this investigation indicate that the structural properties of the Huey-tong bridge belong to Grade I, II, III, and IV which have a membership value of $0.334,0.300,0.191$ and 0.175 , respectively. The structural properties of the Jzyhchyang bridge were attributed to Grade I, II, III, and IV which have a membership value of $0.410,0.337,0.168$, and 0.085 , respectively. The Ay-gwo west road viaduct has the properties of Grade I, II, III, and IV with 0.363 , $0.326,0.193$ and 0.118 , respectively. The old Hwannan viaduct has the properties of Grade I, II, III, and IV with $0.354,0.354,0.198$, and 0.094 , respectively. The order repair and reinforcement about the four existing RC bridges in Taipei is in turn suggested as follows: the Huey-tong bridge, Ay-gwo west road viaduct, old Hwannan viaduct and Jzyh-chyang bridge. As a result, the fuzzy mathematics has the advantage for evaluating the damage state of existing RC bridge.

\section{ACKNOWLEDGMENT}

The authors would like to thank to the National Science Council of the R.O.C for financial support of this study under Contract NSC 89-2211-E-019-015.

\section{REFERENCES}

1. Zadeh, L.A., "Fuzzy Sets," Information and Control, 8, 338-353 (1965).

2. Zadeh, L.A., "Fuzzy Sets As a Basis for a Theory of Possibility," Fuzzy Sets and System, 1(1), 3-28 (1978).

3. Zadeh, L.A., " A Theory of Approximate Reasoning," Machine Intelligence (Hayes, J. E., Michic, D., Mikulich, L. I. Ed. ), 9,149-194 (1979).

4. Yao, J.T.P., "Damage Assessment and Reliability Evaluation of Existing Structures," Journal of Engineering Structures, 1, 245-251 (1979).

5. Yao, J.T.P., "Safety and Reliability of Existing Structures," Pitmen Advanced Publishing Program, London, 129pp. (1985).

6. Tharmabala, T. and Nowak, A.S., "Mathematical Models for Bridge Reliability," Canadian Journal of Civil 
Engineering, 14, 155-162 (1987).

7. Shiaw, S.S., and Huang, W.D., "Synthesis Evaluation of Fuzzy and Random Properties for Bridge Bearing Capacity," Journal of Chiaotung Institute at ChungChing, 1, 64-71 (1990) (in Chinese).

8. Jwu, T.H., Harn, Y., and Liou, W.M., "Fuzzy Evaluation of Reliability of Wharf Structure at Harbor, "Report of Investigation of Corrosion Failure and Its Protection Strategy of Harbor Wharf, Institute of Engineering and Technology of Ten-Jin Waterway, Department of Transportation, 10pp. (1991) (in Chinese).

9. Wang, G.Y., "Theory of Soft Design in Engineering," Science Publisher, Beijing, 70-102 (1992) (in Chinese).

10. Qu, W.J., "Durability Estimation and Service Life Prediction of Existing Concrete Bridges," Ph. D. Dissertation, Southwest Chiaotung University, China, 91-101 (1995) (in Chinese).

11. Zhao, G.F., "Reliability Theory of Engineering Structures and Its Application," Dalian Institute of Science and Technology Publisher, Dalian, China, 290-294 (1996) (in Chinese).

12. Taiwan Construction Research Institute, Testing Evaluation of Road Bridge, Taipei, 1996.

\section{模糊數學評估既有金岡筋混凝土橋樑 之隸屬度}

梁 明德吴家 合

國立䓨灣海洋大學河海工程學系

梁 智 信

國立臺灣海洋大學材料工程研究所

$$
\text { 摘 要 }
$$

本文主要目的是利用模糊數學的概念與思想建 立既有鋼筋混凝土橋樑的損傷評定的方法, 採用評估 等級劃分法則區分評估之結果, 並對橋樑結構的損傷 狀態進行隻層次模糊綜合評判, 再者, 據此綜合評定 結果對橋樑結構的損傷狀態做出了具體的劃分。根據 評估結果, 橋樑損傷的隻層次模糊綜合評判方法, 對 於橋樑之損傷評估有一定之效用, 同時其也可做爲橋 樑維修與補強對策之依據。根據評估之方法, 我們對 台北市之現有之四座橋樑進行評估, 評估的結果顯 示：惠通橋之整體結構性能屬於第I、II、III及IV 级 的隸屬度分別爲 $0.334 、 0.30 、 0.191$ 及 0.175 ; 自強 橋之整體結構性能屬於第I、II、III及IV級的隸屬度 分別爲 $0.41 、 0.337 、 0.168$ 及 0.085 ; 愛國高架橋之 整體結構性能屬於第I、II、III及IV級的隸屬度分別 爲 $0.363 、 0.326 、 0.193$ 及 0.118 ; 舊環南高架橋之整 體結構性能屬於第I、II、III及IV 級的隸屬度分別爲 $0.354 、 0.354 、 0.198$ 及 0.094 。維修與補強的順序爲 惠通橋、愛國高架橋、舊環南高架橋及自強橋, 因 此, 顯然模糊數學具有評估既有鋼筋混凝土橋樑損傷 狀態之優點。 